\title{
THE TREATMENT OF COLLES' FRACTURE
}

\author{
IMMOBILISATION WITH THE WRIST DORSIFLEXED
}

AJAY GUPTA

From LNJP Hospital, New Delhi

\begin{abstract}
In a prospective study, 204 consecutive patients with displaced Colles' fractures had closed reduction then plaster immobilisation. Three different positions of the wrist in plaster were randomly allocated: palmar flexion, neutral and dorsiflexion. The results in the three groups were compared. Fractures immobilised with the wrist in dorsifiexion showed the lowest incidence of redisplacement, especially of dorsal tilt, and had the best early functional results.

Immobilisation of the wrist in palmar flexion has a detrimental effect on hand function; it is suggested that it is also one of the main causes for redisplacement of the fracture. This is discussed in relation to the functional anatomy of the wrist and the mechanics of plaster fixation.
\end{abstract}

Colles' fracture is a very common injury, but there is no agreement on the best way of treatment. A wide variety of methods have been described, including reduction and immobilisation of the wrist and forearm in various positions, percutaneous pinning, external fixation and open reduction with internal fixation.

Although a Colles' fracture can usually be reduced quite easily, it is difficult to maintain the reduction, especially where there is comminution or intra-articular extension. Gartland and Werley (1951) reported that $60 \%$ of their patients healed in an unreduced position.

When the wrist is immobilised in palmar flexion, there is a risk of stiffness of the fingers, and especially the metacarpophalangeal joints. This is a common complication (Gartland and Werley 1951; Bacorn and Kurtzke 1953). Dorsiflexion is the best functional position for the hand, so it was decided to evaluate and compare the results of immobilisation of Colles' fractures in three different positions of the wrist joint: palmar flexion, neutral and dorsiflexion.

\section{PATIENTS AND METHODS}

A prospective study was made of 204 consecutive patients with displaced Colles' fractures at LNJP Hospital, New Delhi from June to November 1986. Of these, 60 were

A. Gupta, MS Orth, Assistant Professor in Orthopaedics Maulana Azad Medical College and LNJPN Hospital, New Delhi 110 002 , India.

(C) 1991 British Editorial Society of Bone and Joint Surgery $0301-620 X / 91 / 2082 \$ 2.00$

J Bone Joint Surg [Br] 1991 ; 73-B:312-5. immobilised with the wrist in palmar flexion, 75 in neutral position and 69 in dorsiflexion. Selection was made on a random basis. There were 122 women and 82 men, with 106 left sided and 98 right sided fractures. The mean age of the patients was 46 years (range 18 to 74 ), evidence of the younger population at risk in India.

Management. Anteroposterior and lateral radiographs were taken of both the injured and the uninjured wrists. The fractures were manipulated under intravenous diazepam and pentazocine sedation, using manual traction with the forearm in pronation. A below-elbow plaster cast was applied, and moulded very carefully around the fracture. The distal radial fragment was pressed in a volar direction with counter pressure against the proximal fragment in a dorsal direction (Fig. 1a). This local moulding holds the fracture in flexion, maintaining the normal anterior tilt of the distal radial articular surface.

While the surgeon was moulding the plaster, an assistant, holding the fingers, moved the wrist to the selected position of palmar flexion, neutral position or dorsiflexion (Fig. 1b). It is essential that the volar pressure is applied to the lower end of the radius and not to the carpal bones. This is best ensured if the wrist is moved into dorsiflexion: volar pressure can then only be applied to the distal radius.

The final movement, as the plaster hardened was to bring the wrist into slight ulnar deviation. At the extremes of flexion or extension of the wrist, the joint is locked (Weber 1984) and ulnar deviation can take place only at the fracture site. This helps to maintain the normal alignment of the distal radial surface. A check radiograph was taken the next day, and again after 10 days. Plaster 


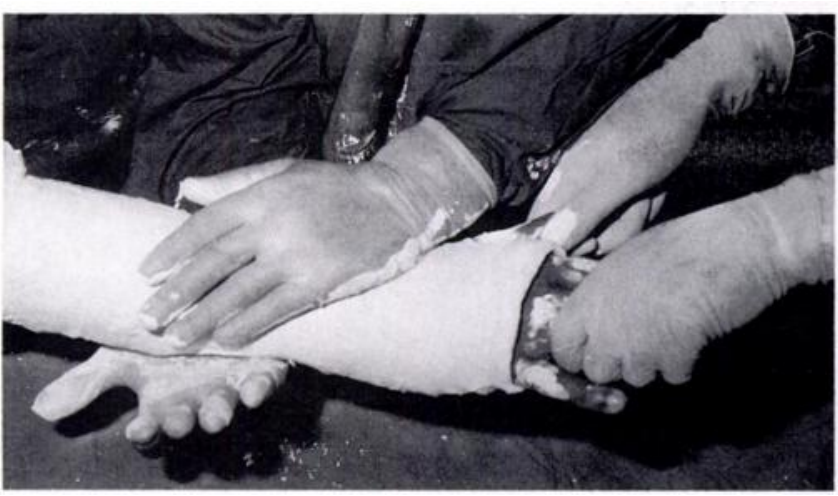

Fig. la

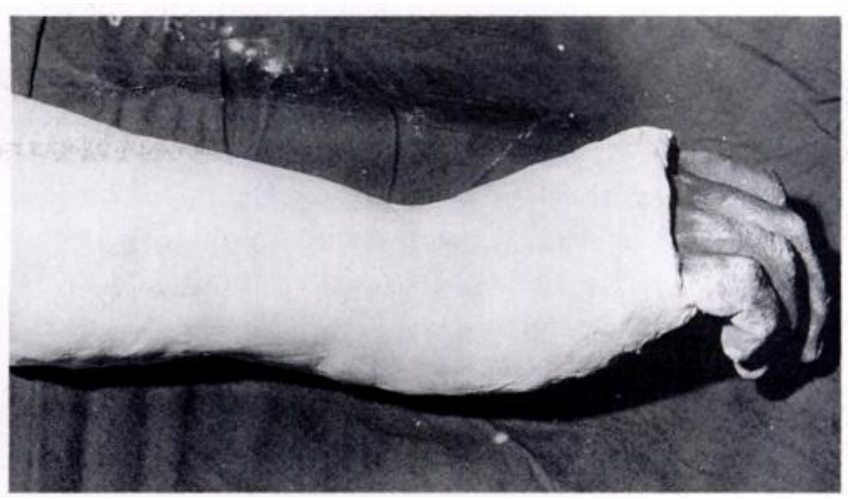

Fig. 1b

Figure 1a - The cast is moulded around the fracture by pressing the distal fragment in a volar direction, with counter pressure on the proximal fragment. Figure $1 \mathrm{~b}$ - A well moulded cast, with the wrist in dorsiflexion making a tube with a double curve in an ' $S$ ' shape.

was kept on for six weeks, except where the fracture was intra-articular, in which case the plaster was removed after five weeks.

Review. Fractures were classified radiographically into five types: type I were undisplaced and extra-articular; type II, undisplaced with intra-articular involvement; type III displaced, extra-articular but with no comminution; type IV, displaced, extra-articular with comminution; and type $\mathrm{V}$ displaced with articular involvement. Types I and II were excluded from the study. There were 94 type III fractures (46\%), 53 type IV (26\%), and 57 type

Table I. Position of immobilisation of the wrist and the type of displaced Colles' fracture

\begin{tabular}{llll}
\hline & \multicolumn{3}{c}{ Type of fracture* $^{*}$} \\
\cline { 2 - 4 } & III & IV & V \\
\hline Palmar flexion $(\mathrm{n}=60)$ & 28 & 17 & 15 \\
Neutral $(\mathrm{n}=75)$ & 34 & 19 & 22 \\
Dorsiflexion $(\mathrm{n}=69)$ & 32 & 17 & 20 \\
Total & 94 & 53 & 57 \\
\hline
\end{tabular}

* III, extra-articular no comminution

IV, extra-articular with comminution $\mathrm{V}$, intra-articular
V $(28 \%)$. The distribution of these types according to position of immobilisation is given in Table $I$.

The average follow-up was 15 months (five months to two years). Measurements of volar tilt, radial deviation and radial length before reduction were made on anteroposterior and lateral radiographs, of the injured and the uninjured wrist. Measurements were repeated on the postoperative, 10-day, and last available review films.

\section{RESULTS}

Anatomical results. The deformities were severe. Before reduction the mean dorsal angulation was $30^{\circ}\left(14^{\circ}\right.$ to $\left.41^{\circ}\right)$, mean radial angulation was $16^{\circ}\left(6^{\circ}\right.$ to $\left.20^{\circ}\right)$ and mean shortening of the radius was $13 \mathrm{~mm}$ ( 5 to 20$)$. Normal volar tilt is $10^{\circ}$ and normal radial angulation is $22^{\circ}$ (van der Linden and Ericson 1981).

Table II shows the loss of position which occurred between the postoperative and the 10-day radiographs. Little difference was found between the 10-day and the latest follow-up films.

In type IV and V injuries the loss of volar tilt was least in fractures immobilised in dorsiflexion (Fig. 2). Volar tilt was usually maintained in this group even if there was significant collapse. Loss of radial angulation was almost the same in all three positions of immobilisation. Loss of radial length was greatest after immobilisa-

Table II. Loss of position in three types of displaced Colles' fracture after immobilisation of the wrist in different positions (mean and range)

\begin{tabular}{|c|c|c|c|c|c|c|c|c|c|}
\hline \multirow{2}{*}{$\begin{array}{l}\text { Position of } \\
\text { immobilisation }\end{array}$} & \multicolumn{3}{|c|}{ Volar tilt (degrees) } & \multicolumn{3}{|c|}{ Radial tilt (degrees) } & \multicolumn{3}{|c|}{ Shortening of radius (mm) } \\
\hline & III & IV & $\mathbf{v}$ & III & IV & $\mathbf{v}$ & III & IV & $\mathbf{v}$ \\
\hline Palmar flexion & $\begin{array}{l}2 \\
0 \text { to } 11\end{array}$ & $\begin{array}{l}8 \\
0 \text { to } 28\end{array}$ & $\begin{array}{l}10 \\
0 \text { to } 32\end{array}$ & $\begin{array}{l}2 \\
0 \text { to } 5\end{array}$ & $\begin{array}{l}5 \\
0 \text { to } 16\end{array}$ & $\begin{array}{l}6 \\
2 \text { to } 14\end{array}$ & $\begin{array}{l}1 \\
0 \text { to } 6\end{array}$ & $\begin{array}{l}4 \\
0 \text { to } 14\end{array}$ & $\begin{array}{l}3 \\
0 \text { to } 11\end{array}$ \\
\hline Neutral & $\begin{array}{l}1 \\
0 \text { to } 8\end{array}$ & $\begin{array}{l}8 \\
0 \text { to } 31\end{array}$ & $\begin{array}{l}6 \\
0 \text { to } 30\end{array}$ & $\begin{array}{l}1 \\
0 \text { to } 3\end{array}$ & $\begin{array}{l}8 \\
0 \text { to } 17\end{array}$ & $\begin{array}{l}8 \\
2 \text { to } 18\end{array}$ & $\begin{array}{l}2 \\
0 \text { to } 8\end{array}$ & $\begin{array}{l}6 \\
0 \text { to } 18\end{array}$ & $\begin{array}{l}8 \\
0 \text { to } 18\end{array}$ \\
\hline Dorsiflexion & $\begin{array}{l}1 \\
0 \text { to } 9\end{array}$ & $\begin{array}{l}2 \\
0 \text { to } 10\end{array}$ & $\begin{array}{l}3 \\
0 \text { to } 11\end{array}$ & $\begin{array}{l}2 \\
0 \text { to } 6\end{array}$ & $\begin{array}{l}5 \\
1 \text { to } 13\end{array}$ & $\begin{array}{l}4 \\
0 \text { to } 12\end{array}$ & $\begin{array}{l}1 \\
0 \text { to } 3\end{array}$ & $\begin{array}{l}2 \\
0 \text { to } 8\end{array}$ & $\begin{array}{l}2 \\
0 \text { to } 10\end{array}$ \\
\hline
\end{tabular}


tion in the neutral position and least in those immobilised in dorsiflexion (Table II). In the type III fractures (extraarticular, no comminution) the position of immobilisation of the wrist made no significant difference.

Functional results. These were assessed by the criteria of Sarmiento et al (1975). Fractures immobilised with the wrist in dorsiflexion had the best results (Table III). Comparison of various joint movements with those on the uninjured side showed that fractures immobilised in palmar flexion had more joint stiffness, particularly of the metacarpophalangeal and interphalangeal joints. Even in Type III fractures, where the position of immobilisation of the wrist did not significantly affect the anatomical result, immobilisation in dorsiflexion provided the best recovery of function (Table III).

\section{DISCUSSION}

Colles' fracture can be difficult to treat: the major problem is maintenance of reduction. This is partly due to its anatomical site, adjacent to the multilinked system of the carpus, and partly to our poor understanding of the mechanics of the fracture itself.

The carpal bones transmit forces from the hand to the forearm, but are under no direct motor control. The main force-bearing column of the wrist includes the distal radial articular surface, the lunate and the proximal twothirds of the scaphoid, the capitate, the trapezoid and the joints of the second and third metacarpals (Weber 1984). Colles' fracture breaks the continuity of this column proximally, so the main muscle forces influencing displacement are those acting on the whole column. These are the wrist flexors and extensors inserted at the bases of the second and third metacarpals.

After a Colles' fracture, whatever the position of the wrist, the extensors of the carpus tend to increase the posterior displacement of the fracture while the wrist flexors act in the direction of over reduction. The radial extensors of the wrist are more powerful than the radial flexors (Von Lanz and Wachsmuth 1959). This implies that the best position for immobilisation with balanced forces is dorsiflexion, where the wrist extensors are placed at a relative mechanical disadvantage.

The periosteal hinge on the concave, dorsal side of a Colles' fracture can be an important stabilising factor. When it is intact, it prevents over reduction; it should be exploited by being kept under tension by slight volar angulation at the fracture. Tension can be maintained in the periosteal hinge by moulding the plaster in the direction of over correction. Flexion at the fracture site is important since it makes the best use of the dorsal periosteal hinge, but the flexed position need not be maintained at the wrist joint.

When the wrist is palmar flexed the dorsal carpal ligament, attached mainly to the dorsal aspect of the triquetrum, limits flexion of the proximal carpal row, so that most palmar flexion takes place at the mid-carpal

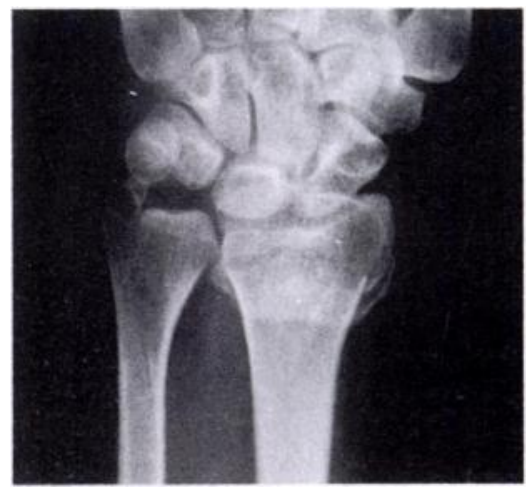

Fig. 2a

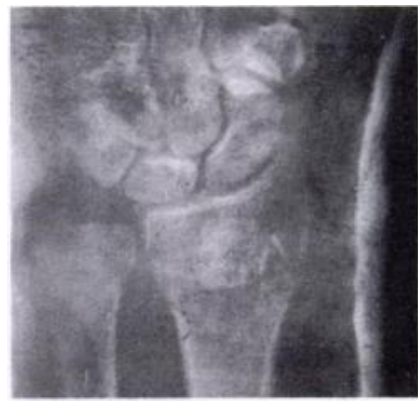

Fig. 2c

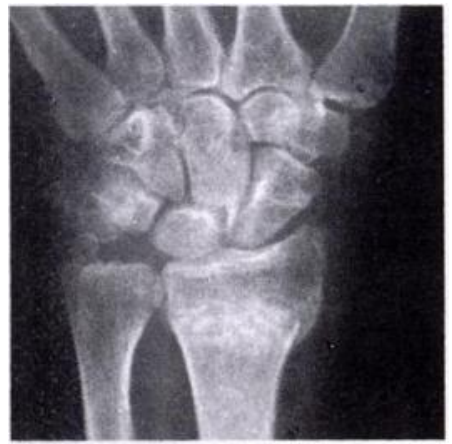

Fig.2e

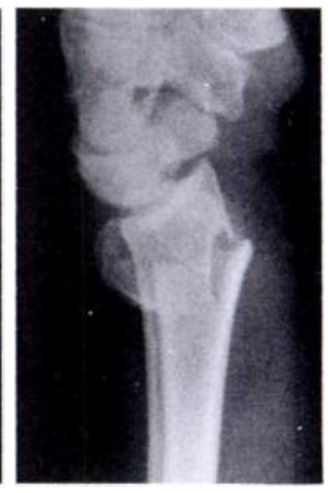

Fig. 2b

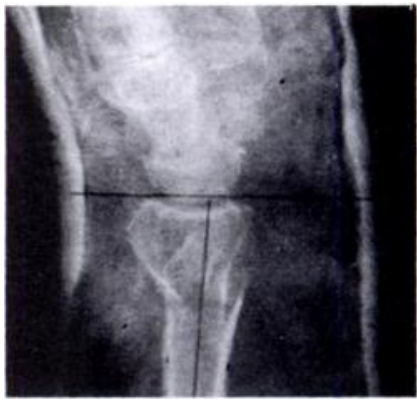

Fig. $2 d$

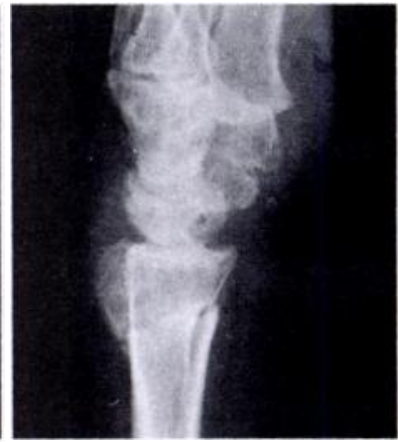

Fig. $2 \mathrm{f}$
Radiographs of a type IV fracture. Figures $2 a$ and $b$ - Before reduction. Figures $2 c$ and $d-$ The wrist in dorsiflexion in a below-elbow cast. Correction of volar tilt has been possible only to $0^{\circ}$. Figures $2 \mathrm{e}$ and $\mathrm{f}-$ Final radiograph shows healing with no further deterioration in the volar tilt.

Table III. Functional results in displaced Colles' fractures after immobilisation with the wrist in different positions, showing number and percentage of each treatment group

\begin{tabular}{|c|c|c|c|c|c|c|c|c|c|c|c|c|}
\hline \multirow{2}{*}{$\begin{array}{l}\text { Type of } \\
\text { fracture }\end{array}$} & \multicolumn{4}{|c|}{ Palmar flexion* } & \multicolumn{4}{|c|}{ Neutral position } & \multicolumn{4}{|c|}{ Dorsiflexion } \\
\hline & $\mathbf{E}$ & G & $\mathbf{F}$ & $\mathbf{P}$ & $\mathbf{E}$ & $\mathbf{G}$ & $\mathbf{F}$ & $\mathbf{P}$ & $\mathbf{E}$ & G & $\mathbf{F}$ & $\mathbf{P}$ \\
\hline III & 9 & 11 & 7 & 1 & 13 & 13 & 7 & 1 & 20 & 8 & 4 & 0 \\
\hline IV & 5 & 5 & 3 & 4 & 4 & 4 & 8 & 3 & 9 & 6 & 2 & 0 \\
\hline \multirow[t]{2}{*}{$\mathbf{V}$} & 5 & 4 & 2 & 4 & 6 & 7 & 5 & 4 & 11 & 5 & 3 & 1 \\
\hline & 19 & 20 & 12 & 9 & 23 & 24 & 20 & 8 & 40 & 19 & 9 & 1 \\
\hline Percentage & 34 & 33 & 20 & 13 & 30 & 32 & 27 & 11 & 58 & 28 & 13 & 1 \\
\hline
\end{tabular}

*E, excellent; G, good; F, fair, P, poor 


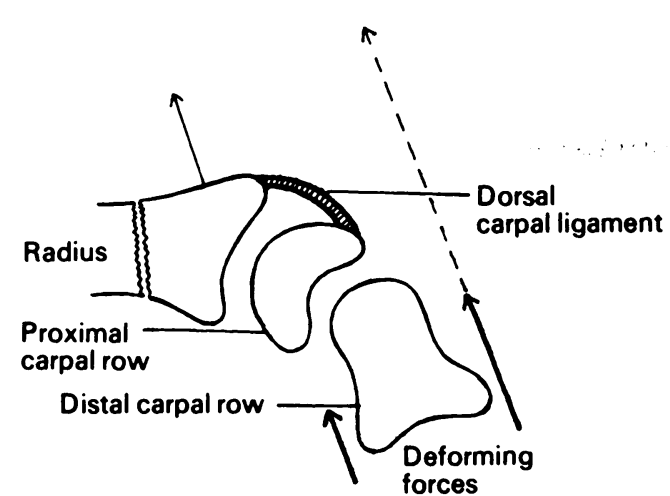

PALMAR FLEXION

Fig. 3a

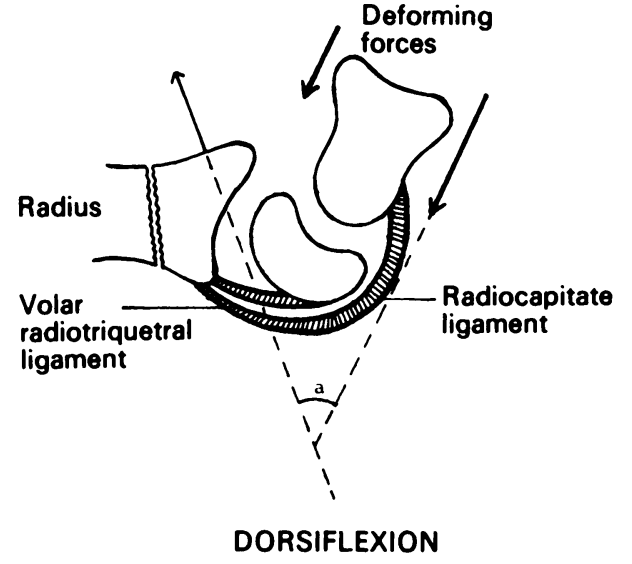

Fig. 3b

In palmar flexion the dorsal carpal ligament is taut, but cannot stabilise the fracture because of its lack of an attachment to distal carpal row. The deforming forces and the potential displacement of the fracture are parallel, in the same direction. In dorsiflexion, the volar ligaments are taut and tend to pull the fracture fragment anteriorly. The deforming forces act at an angle which tends to reduce the displacement of the fracture.
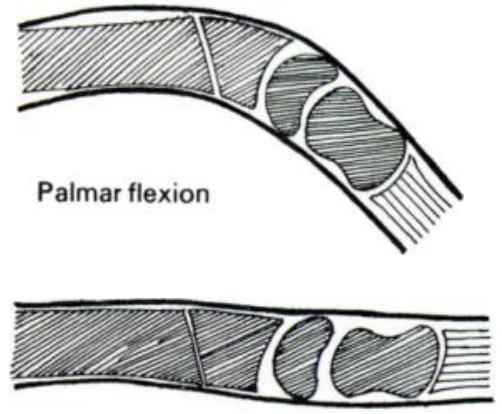

Neutral

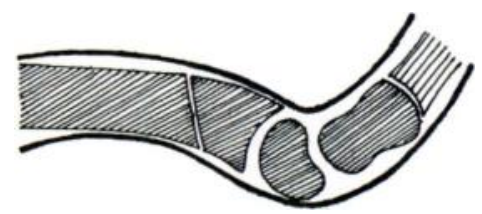

Dorsiflexion

Fig. 4

The fracture will collapse most easily inside a straight tube. When the wrist is dorsiflexed, the plaster forms a tube with a double curve in an ' $S$ ' shape.

articulation, where there is no dorsal ligament (Fig. 3a). This lack of control at mid-carpal level allows the strong radial extensors of the wrist to rotate the proximal row of the carpus, together with the distal radial fragment, into extension, with consequent loss of reduction.

By contrast, when the wrist is dorsiflexed the volar radiotriquetral and radiocapitate ligaments become taut: these stabilise both rows of the carpus with respect to the radius, and resist any deforming forces by providing a volar pull on the distal fracture fragment (Fig. 3b). Moreover, forces applied in the line of the dorsiflexed carpus act at an angle which tends to reduce the fracture. In palmar flexion these forces act in a direction tending to increase displacement (Figs $3 a$ and $3 b$ ).

In a grossly comminuted fracture some collapse is probably inevitable, but this is likely to be minimised when the wrist is immobilised in dorsiflexion. Figure 4 shows that collapse or impaction, especially of the dorsal cortex, is more likely inside a straight or smoothly curved tube than in a tube with a double curve in an ' $S$ ' shape. Conclusion. After manipulation of a Colles' fracture, immobilisation of the wrist in dorsiflexion would appear to provide better maintenance of reduction. Further trials and evaluation are required.

No benefits in any form have been received or will be received from a commercial party related directly or indirectly to the subject of this article.

\section{REFERENCES}

Bacorn RW, Kurtzke JF. Colles' fracture : a study of two thousand cases from the New York State Workman's Compensation Board. $J$ Bone Joint Surg [ Am] 1953; 35-A :643-58.

Gartland JJ Jr, Werley CW. Evaluation of healed Colles' fractures. J Bone Joint Surg [Am] 1951 ; 33-A :895-907.

Sarmiento A, Pratt GW, Berry NC, Sinclair WF. Colles' fractures: functional bracing in supination. J Bone Joint Surg [Am] 1975; 57 A:311-7.

van der Linden W, Ericson R. Colles' fracture: how should its displacement be measured and how should it be immobilized? $J$ Bone Joint Surg [Am] 1981; 63-A :1285-8.

Von Lanz T, Wachsmuth W. Praktische Anatomie. 2nd ed. Berlin Springer-Verlag, 1959.

Weber ER. Concepts governing the rotational shift of the intercalated segment of the carpus. Orthop Clin North Am 1984; 15:2:193-207. 